
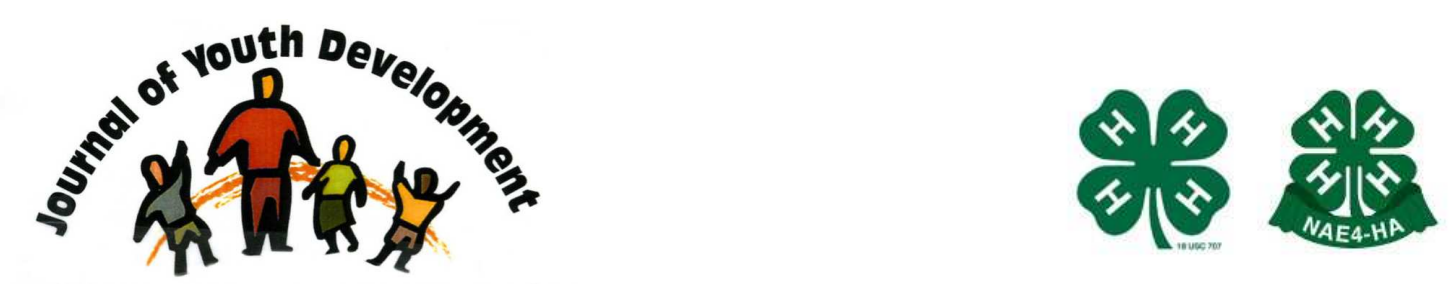

Bridging Research \& Practice

\title{
The Changing Landscape of Peer Aggression: A Literature Review on Cyberbullying and Interventions
}

\author{
Katie Davis \\ The Information School \\ University of Washington \\ Seattle, WA \\ kdavis78@uw.edu \\ Justin Reich \\ Berkman Center for Internet \& Society \\ Harvard University \\ Cambridge, MA \\ justin reich@harvard.edu \\ Carrie James \\ Harvard Graduate School of Education \\ Cambridge, MA \\ carrie james@harvard.edu
}




\title{
JOURNAL OF YOUTH DEVELOPMENT \\ bridging research and practice

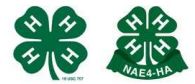

Volume 9, Number 1, Special Edition

Article 140901FA009

\section{The Changing Landscape of Peer Aggression: A Literature Review on Cyberbullying and Interventions}

\author{
Katie Davis \\ University of Washington \\ Justin Reich \\ Berkman Center for Internet \& Society \\ Carrie James \\ Harvard Graduate School of Education
}

\begin{abstract}
While traditional forms of bullying have been steadily decreasing over the course of the last two decades, cyberbullying has emerged as a major concern among parents, teachers, and other professionals working with young people. Because cyberbullying is a relatively new phenomenon, its research base is not as well developed as research on traditional bullying. In this literature review, the authors synthesize current knowledge on cyberbullying's prevalence among youth; its relationship to offline bullying; which youth are most likely to be perpetrators and victims; the negative effects of cyberbullying on victims; and the landscape of intervention efforts currently employed in the United States. In the process, they highlight areas in need of future research.
\end{abstract}

\section{Introduction}

In recent years, a number of high-profile teen suicides have drawn public attention to a new, high-tech form of an age-old problem: bullying. While traditional forms of bullying have been steadily decreasing over the course of the last two decades (Finkelhor, 2013; Molcho, et al., 2009; Rigby, \& Smith, 2011), cyberbullying has emerged as a major concern among parents, teachers, and other professionals working with young people (Willard, 2007). Indeed, 16 states have passed cyberbullying laws in recent years, and 47 states have laws that address "electronic harassment" (Hinduja, \& Patchin, 2011). This article reviews existing research and 
school-based interventions around cyberbullying in an effort to document both the scope of the problem and current efforts to address it. Through this review, we aim to identify areas for future research that will inform the development of successful anti-cyberbullying initiatives.

\section{Bullying, then and now}

Bullying has been around as long as recess, lunch, and the bus ride to school, and has been the subject of empirical study and active intervention for several decades (Olweus, 1978, 1993, 1994; Smith, Madsen, \& Moody, 1999; Smith, Talamelli, Cowie, Naylor, \& Chauhan, 2004. In recent years, the landscape of bullying has started to change. With respect to traditional forms of bullying, there is cause for some optimism. One study of international time trends in rates of bullying among 11-, 13-, and 15-year-old school-children found decreases in reported rates of bullying and victimization between 1993/4 and 2005/6 in the majority of the 27 participating countries, including the United States (Molcho, et al., 2009). Here, bullying refers to the perpetration of bullying behaviors, whereas victimization refers to individuals who are on the receiving end of bullying behaviors. Another study found similar downward trends in bullying among adolescents in a variety of countries, including England, Wales, Spain, Australia, and the United States (Rigby, \& Smith, 2011).

In the U.S. specifically, the annual National Crime Victimization Survey (NCVS) showed a 74\% decline between 1992 and 2010 in school-related violent victimizations among 12-18-year-olds, and an $84 \%$ decline in school-related thefts (Finkelhor, 2013). The NCVS also showed a decline of $29 \%$ from 2001 to 2009 in the number of youth who reported being the target of haterelated words at school.

It appears that bullying and victimization have dropped more steeply for U.S. boys than U.S. girls. Between $1997 / 98$ and $2005 / 06$, bullying dropped by $15.5 \%$ (occasional) and $37.4 \%$ (chronic) for boys, and 4.1\% (occasional) and 16.7\% (chronic) for girls (Molcho, et al., 2009). Similarly, victimization dropped by $24.7 \%$ (occasional) and $27.0 \%$ (chronic) for boys, but only $0.7 \%$ (occasional) and 3.6\% (chronic) for girls.

Despite these welcome declines, bullying is still far too prevalent among young people living in the United States. In a nationally representative sample of 11-15 year-olds, nearly three out of every ten youth ( $29.9 \%$ of boys, $29.2 \%$ of girls) reported experiencing occasional victimization in $2005 / 6$, and approximately one out of ten youth (11.9\% of boys, $10.9 \%$ of girls) reported experiencing chronic victimization (Molcho, et al., 2009). In another national study of 6-17 yearolds, an average of $25 \%$ of youth respondents said they were bullied at least monthly (Ybarra, boyd, Korchmaros, \& Oppenheim, 2012a).

\section{The emergence of cyberbullying}

While traditional bullying has been declining, a new form of bullying has emerged as broadband internet access, mobile devices, and social media platforms have swept across the developed world. Though rates of cyberbullying are still generally lower than traditional forms of bullying (Wang, Iannotti, \& Nansel, 2009; Ybarra, et al., 2012a; Ybarra, Mitchell, \& Espelage, 2012b), the limited available data suggest they are on the rise. Among nationally representative samples of U.S. internet users aged $10-17$ years, rates of reported online harassment increased by $83 \%$ over the course of the preceding decade, from $6 \%$ in 2000 to $9 \%$ in 2005 to $11 \%$ in 2010 (Finkelhor, 2013; Jones, Mitchell, \& Finkelhor, 2012). Another national study of 6-17 year-olds found that an average of $10 \%$ said they were bullied at least monthly online (Ybarra, et al., 2012a). 
The rates are higher when researchers look more broadly at meanness online (Levy, et al., 2012). For instance, a national survey conducted in 2011 by MTV showed that more than half (56\%) of young people aged 14-24 years have experienced verbal abuse through social media, and the majority of them (53\%) said that the experience was deeply upsetting (AP-MTV, 2011). In another 2011 survey, conducted by the Pew Research Center, 88\% of teens aged 12-17 years who use social media said that they had witnessed other people being mean or cruel on a social networking site (Lenhart, et al., 2011).

What is cyberbullying?

Traditional bullying is characterized by three key features:

1) intentionally hurtful actions that are

2) repeated over time and

3) involves a power imbalance between perpetrator and victim (Olweus, 1978, 1993, 2003).

Bullying involves either physical or psychological harm, and it can be direct or indirect (Smith, 2009). In contrast, peer aggression does not always involve a power imbalance, and it is not necessarily repeated over time.

Because cyberbullying is still a relatively new phenomenon, its definition is less fixed (Levy, et al., 2012). Indeed, even the term "cyberbullying" is not set in stone, with some scholars opting to use alternative terms such as internet bullying (Williams, \& Guerra, 2007), social media meanness (Lenhart, et al., 2011), digital abuse (AP-MTV, 2011), or drama (Marwick, \& boyd, 2011). In their definition of drama, Marwick and boyd (2011) note that drama does not always overlap with bullying, and it is usually but not always carried out in networked publics.

Extant definitions of cyberbullying generally draw on definitions of traditional bullying (Levy, et al., 2012; Tokunaga, 2010). At the same time, digital media introduce new dynamics that make cyberbullying distinct from traditional bullying (Dooley, Pyzalksi, \& Cross, 2009; Willard, 2007). Consider one of the standard features of traditional bullying: repetition. On the one hand, the round-the-clock nature of networked communication offers unprecedented opportunities for repeated acts of bullying (Tokunaga, 2010). At the same time, just one embarrassing picture posted on the internet may feel like a repetitive act of bullying as it persists online and circulates among ever-wider audiences (Dooley, et al., 2009).

The power imbalance that is characteristic of traditional bullying is also complicated in online settings. For instance, both the inability to find respite from cyberbullying and the inability to identify one's tormentor may each contribute to the victim's sense of powerlessness (Dooley, et al., 2009). Even when bullies are recognized by their victims-as research suggests they often are (Juvonen, \& Gross, 2008; Ybarra, et al., 2012b) -the arm's-length nature of asynchronous, screen-based communication may embolden perpetrators and increase the severity of their hurtful comments. Indeed, MTV's 2011 survey showed that $71 \%$ of youth say that people are more likely to use racist or sexist slurs online or through text messaging than in person (APMTV, 2011).

Another distinguishing characteristic of cyberbullying is the relative lack of adult supervision in online settings (Tokunaga, 2010). Whereas school administrators and teachers are generally the ones to keep an eye out for and intervene in instances of schoolyard bullying, mediated settings are not so visible to these parties. Much of what youth do online takes place across geographic spaces and outside the view of adults. Moreover, our professional development work with 
educators suggests that they find it difficult to keep track of the popular online spaces that youth frequent as they migrate from MySpace to Facebook to Twitter, Tumblr, and Snapchat. Even when adults know about these sites, young people's use of privacy settings and their expectations of privacy from teachers and parents online pose distinct challenges for adult supervision (boyd, \& Marwick, 2011; Davis, \& James, 2013). Indeed, youth perceptions of certain online spaces as "youth only" spaces may help to explain why most youth do not seek adult assistance when they experience cyberbullying (Holfeld, \& Grabe, 2012; Juvonen, \& Gross, 2008; Levy, et al., 2012; Tokunaga, 2010). Within the context of this supervision vacuum, perpetrators' power increases along with their freedom to commit repeated acts of bullying.

\section{Youth's conceptions of cyberbullying}

While scholars negotiate the meaning, purview, and distinct characteristics of cyberbullying, young people may be developing a somewhat different understanding. Yet, Agatston, Kowalski, and Limber (2012) observe that there has been relatively little qualitative research exploring youth's perspectives about cyberbullying. A notable exception involves five years of ethnographic work with youth between the ages of 13 and 19 years (Marwick, \& boyd, 2011). Through their interviews with youth participants, the researchers discovered that many young people actively distance themselves from terms like "bullying" and "cyberbullying." They view these as adult labels used to identify perpetrators and victims, and they are resistant to viewing themselves as either. As a result, behaviors that researchers and educators would classify as cyberbullying are instead referred to as "drama" by young people. This semantic turn allows youth to distance themselves from the gravity that adults attach to cyberbullying and to maintain their sense of themselves as neither a bully nor a victim.

More generally, there is evidence that youth norms around online conduct are more lax and playful than in offline contexts (AP-MTV, 2011; Davis, 2012c). The MTV survey discussed earlier found that while youth report encountering more derogatory language online, most write it off as simply joking (AP-MTV, 2011). Our own research uncovered a similar dynamic. When we presented our youth participants with a hypothetical scenario that involved inflammatory language, most of them discounted it as a joke (Davis, 2012c). This stance may disincline youth from interpreting their own and others' online actions as bullying behavior, even if they are interpreted as such by those on the receiving end (Vandebosch, \& van Cleemput, 2009).

These insights from existing research underscore the importance of seeking youth perspectives in any subsequent research on cyberbullying and associated school-based interventions. For an anti-cyberbullying initiative to succeed, it must resonate with students' lived experiences and the meanings they ascribe to them.

\section{Who is involved in cyberbullying, and how?}

From the prevalence rates reported above, cyberbullying clearly does not involve all young people. Efforts to address cyberbullying will thus benefit from insight into which youth are most at risk of being perpetrators and victims. First, there is evidence that instances of cyberbullying are often grounded in offline peer dynamics (Marwick, \& boyd, 2011; Tokunaga, 2010), and that victims often know their online bullies from offline contexts like school (Juvonen, \& Gross, 2008; Ybarra, et al., 2012b). Indeed, Vandebosch and van Cleemput (2009) found that online bullies are more likely to be offline bullies, and online victims are more likely to be offline victims. 
In one study of 1,454 youth aged $12-17$ years living in Colorado, fully $85 \%$ of those who had reported at least one instance of being bullied online in the last year said they had also been bullied in school (Juvonen, \& Gross, 2008). Another study involving a nationally representative sample of $10-15$ year-olds found that $36 \%$ reported experiencing both traditional and cyberbullying simultaneously (Ybarra, Diener-West, \& Leaf, 2007). Though that leaves nearly two-thirds of youth who did not experience both forms of bullying, the findings nevertheless indicate that a sizable number of youth are victims both online and offline.

It is not always the case that the victim and bully roles are played by the same individuals online as offline. In some cases, online perpetrators report being the victims of offline bullying, explaining that their aggressive behavior was motivated by a desire to seek revenge on their offline tormentors (Vandebosch, \& van Cleemput, 2008) or simply people who have annoyed them (Raskauskas, \& Stoltz, 2007). In light of this finding, it may be that the role of "bullyvictim"-where youth are both bullies and victims -is particularly prominent online (Levy, et al., 2012). It also suggests that youth who would not otherwise engage in bullying behavior offline feel emboldened to engage in such behavior online (Vandebosch, \& van Cleemput, 2008).

Beyond the roles of bully, victim, and bully-victim, there is evidence to suggest that many youth act as bystanders to cyberbullying (Lenhart, et al., 2011; Vandebosch, \& van Cleemput, 2009). As bystanders, they avoid involving themselves directly in the bullying situation (Twemlow, Fonagy, \& Sacco, 2004). This role stands in contrast to the upstander, who actively intervenes in a bullying situation, for example, by publicly expressing disapproval of the bullying behavior (Diazgranados Ferrans, Selman, \& Feigenberg, 2012). In offline situations, research suggests that youth are more likely to act as bystanders, even when they express a desire to be an upstander (Diazgranados Ferrans, et al., 2012; O'Connell, Pepler, \& Craig, 1999). The same seems to be true in online contexts. In one study of Flemish youth aged 10-18 years, $76.3 \%$ who had experienced at least one instance of potentially offensive internet or mobile phone practice (POP) during the previous three months reported being bystanders. Among American youth, a 2011 survey found that fully $90 \%$ of youth using social media said they ignore meanness when they witness it online (Lenhart, et al., 2011).

These high rates of bystanding may relate to youth's tendency to discount much of what they encounter online as simply a joke (AP-MTV, 2011; Davis, 2012c). Bystanding behavior may also relate to the arm's-length nature of computer-mediated communication; research shows that when youth are not emotionally affected by bullying, they are less likely to intervene (Barhight, Hubbard, \& Hyde, 2013). Similarly, Diazgranados Ferrans, Selman, \& Feigenberg (2012) found that students were more likely to bystand when their universe of moral responsibility did not extend to "nonfriends," and when they believed that their power in the peer group was not sufficiently high to be able to challenge the perpetrator. It is possible that certain online environments foster perceptions of other participants as "nonfriends" while simultaneously diminishing one's own sense of agency to intervene in a bullying situation. Future research is needed to determine whether these offline dynamics of bystanding behavior apply to online contexts, as well as the particular circumstances that promote bystanding versus upstanding behavior online.

\section{Demographic predictors of cyberbullying}

Traditional bullying typically peeks during the transition to middle school and then declines during high school (Pellegrini, 2002; Pellegrini, \& Long, 2002; Smith, Madsen, \& Moody, 1999). Though most studies show no connection between age and cyberbullying, Tokunaga (2010) suggests that the lack of correlation may in fact be due to the presence of a curvilinear 
relationship. According to his meta-synthesis of quantitative studies on cyberbullying, Tokunaga points to seventh and eighth grades as the period of greatest risk for cyberbullying. Providing empirical support for this claim, one study of 3,339 youth in Grades 5, 8, and 11 in Colorado found that both offline and online forms of bullying perpetration were highest among eighth graders (Williams, \& Guerra, 2007). With respect to online bullying, fifth graders were least likely to report bullying perpetration (4.5\%), eighth graders were most likely $(12.9 \%)$, and eleventh graders fell in between (9.9\%). This research suggests that middle school is an important time to investigate and intervene in youth cyberbullying.

In addition to age, gender is also a common predictor of traditional bullying, with boys more likely than girls to be both bullies and victims (Cook, et al., 2010). Though evidence relating to the role of gender in cyberbullying is inconsistent (Levy, et al., 2012; Pedersen, 2013), a number of studies show that girls are somewhat more likely than boys to report being bullied online (Davis, 2012a; Holfeld, \& Grabe, 2012; Snell, \& Englander, 2010; Tokunaga, 2010).

With respect to other demographic predictors of cyberbullying, the research is sparse. An early study of cyberbullying found no statistically significant differences in rates of cyberbullying across race, though the researchers noted that their sample was relatively homogeneous (Patchin, \& Hinduja, 2006). A more recent study found that African-American adolescents were more likely to be involved in bullying perpetration (physical, verbal, and cyber) than Caucasian adolescents, but less likely to be involved in verbal and relational victimization (Wang, et al., 2009). The researchers also found that Hispanic adolescents were more likely to be physical bullies or cyber bully-victims than Caucasian adolescents. Adolescents in the "other" race/ethnicity category were less likely than Caucasian adolescents to be relational bullies or verbal bully-victims, but more likely to be the targets of cyberbullying.

Other studies have found that youth with intellectual and developmental disabilities are at greater risk of cyberbullying victimization (Didden, et al., 2009; Kowalski, \& Fedina, 2011). There is also evidence that youth who experience offline harassment based on their sexuality experience such harassment online, too (Pascoe, 2011). One study of 11-18 year-olds in a large public school district in the U.S. found that almost twice as many LGBT students reported experiencing cyberbullying compared to heterosexual students (Hinudja, \& Patchin, 2011). In order to target cyberbullying efforts effectively, considerably more research is needed to identify which youth are most at risk and under what circumstances.

\section{Effects of cyberbullying}

Like traditional bullying, cyberbullying is associated with a variety of negative outcomes for youth, including depression, social anxiety, substance use, lowered academic performance, and diminished quality of family relationships (Bonanno, \& Hymel, 2013; Tokunaga, 2010; Wolke, Copeland, Angold, \& Costello, 2013). In a national study of 1,501 internet users aged 10-17 years, for instance, researchers found that online and offline victimization were independently related to depressive symptomatology, delinquent behavior, and substance use (Mitchell, Ybarra, \& Finkelhor, 2007). In another study of U.S. teens aged 12-17 years, offline victimization and cyberbullying victimization each independently contributed to elevated levels of social anxiety (Juvonen, \& Gross, 2008). Other studies have found a relationship between cyberbullying and a range of academic problems, such as declining grades and increased absences and truancy (Beran, \& Li, 2005; Katzer, Fetchenhauer, \& Belschak, 2009). 


\section{School-based bullying interventions}

The many years of research on traditional bullying and bullying interventions have resulted in a set of well-supported strategies and practices for preventing and addressing bullying in schools. Successful strategies generally adopt a whole-school approach, target school climate and peer influences, and seek to change peer norms around bullying (Swearer, Espelage, Vaillancourt, \& Hymel, 2010). Specific practices include classroom rules, classroom management, school conferences, playground supervision, disciplinary methods, parent meetings, and information for parents (Farrington, \& Ttofi, 2009). Programs that incorporate several of these practices, and do so with a longer duration and higher intensity, are the most effective at decreasing bullying in schools. In their meta-analysis of the effectiveness of anti-bullying programs in schools, Ttofi and Farrington (2011) found that anti-bullying programs have generally met with success at decreasing bullying.

A foundational and extensively researched anti-bullying program is the Olweus Bullying Prevention Program (Limber, 2011; Olweus, 1994). A pioneer in the research on school bullying, Dan Olweus and his colleagues developed the program in the mid-1980s around four core, research-based principles. These principles focus on creating a school environment that is marked by: "warmth, positive interest, and involvement from adults; firm limits on unacceptable behavior; consistent application of nonpunitive, nonphysical sanctions for unacceptable behavior or violations of rules; and adults who act as authorities and positive role models" (Olweus, 2003, p.15). To achieve success, the program relies on teachers, administrators, students, and parents to work together to strengthen the school climate.

Such evidence-based programs are not fool-proof, however. Swearer, et al. (2010) observe that some schools that employ well-established bullying programs still struggle with bullying among students. They attribute the persistence of bullying in part to schools' failure to take a socialecological approach to bullying prevention. Swearer et al. suggest that schools would be well advised to take into account the various social contexts and dynamics that youth experience beyond school that may sustain bullying. In the year 2013, this requires paying attention to the social contexts that youth experience online.

\section{Cyberbullying interventions}

In recent years, there have emerged interventions geared specifically to cyberbullying, for example, i-SAFE, Netsmartz, WebWiseKids, and Common Sense Media's Digital Literacy and Citizenship Curriculum. These programs encourage youth to focus on positive uses of technology; recognize and exercise their own agency online; empathize with would-be cybervictims; upstand rather than bystand when they witness cyberbullying; and maintain open lines of communication with adults about their online experiences (Walker, 2012).

Just how widespread these anti-cyberbullying efforts are and whether or not they are meeting with success remain unclear (Walker, 2012). In their literature review on bullying in a networked era, Levy, et al. (2012) note that literature addressing school policies around cyberbullying generally states what these policies should include rather than what they actually include. This state of affairs suggests a need to document systematically what U.S. schools are doing to address cyberbullying, as well as how their efforts are being received by youth.

From the above discussion, it is evident that adult intervention plays an important role in traditional anti-bullying efforts, as does creating school and peer norms that undercut bullying behavior. Yet, each of these prevention strategies faces specific challenges when it comes to cyberbullying. First, it is difficult for adults to intervene when $90 \%$ of youth never tell an adult 
that they have experienced cyberbullying (Juvonen, \& Gross, 2008). Reasons for this silence include a fear of losing internet privileges and the perception that only "kids" tell adults about problems online (Tokunaga, 2010). Another challenge to adult intervention is the fact that cyberbullying may not take place on school grounds, raising questions about the degree to which school personnel can and should intervene in such situations (Couvillon, \& Ilieva, 2011).

Second, as noted earlier, the youth norms that have emerged around online conduct are such that young people may be resistant to seeing their actions as bullying behavior (Marwick \& boyd, 2011; Vandebosch, \& van Cleemput, 2009). The challenge, therefore, is to find a way to bridge the gulf between adult-defined "cyberbullying" and youth-defined "drama" and "joking."

The distinct properties of online environments-such as asynchronous communication, roundthe-clock connectivity, the ease of anonymity, and an ill-defined, potentially large audiencepose further challenges to intervention efforts. It is unclear how well strategies designed to address offline situations apply to online contexts. For instance, StopBullying.Gov has a page of advice about "Supporting Bystanders who Witness Bullying"

(http://www.stopbullying.gov/respond/support-kids-involved/index.html\#bystanders).

Suggestions include:

- Help the person being bullied get away from the situation.

- Take away the audience by choosing not to watch and walk away.

- Tell the child doing the bullying that you don't like it and to stop doing it (but only if it feels safe to do so).

While these guidelines may be informed by research on effective approaches for addressing bullying offline, it is not clear that they translate as effectively to an online context. For instance, what does it mean to help a person being bullied online to "get away from the situation?" Does it mean encouraging youth to power down? Giving them alternative conversation streams to participate in? This may be hard for youth, for whom social media have become a focal point of their social lives (Davis, 2012b; Slonje, \& Smith, 2008).

Similar questions arise for the other suggestions in the list. What does it mean to "take the audience away" when the audience is a more abstract concept? How does "upstanding" and confronting bullying or cruel behavior make sense in an online context? Should children confront cyberbullies online? Or should they confront them later in the physical world? What assumptions do youth have about the efficacy and risks of online upstanding? Do educators share those assumptions? The dissonance between research-based advice generated for a prenetworked world and the experiences of children who move fluidly between online and physical social settings represents a central tension that is worth exploring in future research.

\section{Conclusion}

This review points to several gaps in the existing literature on cyberbullying among today's young people. In particular, we need a better understanding of which youth are most at risk of being bullies, victims, and bystanders online, as well as the circumstances under which youth are most likely to upstand against cyberbullying behavior. An important component of this research must involve documenting the characteristics of existing anti-cyberbullying efforts currently employed in U.S. schools and youth's reception of these initiatives. This insight will help determine which interventions are worth strengthening and expanding and which should be replaced. 


\section{Acknowledgements}

The authors wish to thank Terri Northcut for her aid in reviewing literature for this article.

\section{References}

Agatston, P.W., Kowalski, R., \& Limber, S. (2012). Youth views on cyberbullying. In J.W. Patchin \& S. Hinduja (Eds), Cyberbullying prevention and response: Expert perspectives (pp. 57-71). New York: Routledge.

Associated Press-MTV Digital Abuse Survey. (2011, August). Conducted by Knowledge Networks, Palo Alto, CA. Available at: http://www.athinline.org/pdfs/MTVAP 2011 Research Study-Exec Summary.pdf

Barhight, L.R., Hubbard, J.A., \& Hyde, C.T. (2013). Children's physiological and emotional reactions to witnessing bullying predict bystander intervention. Child Development, 84(1), 375390.

Beran, T., \& Li, Q. (2005). Cyber-harassment: A study of a new method for an old behavior. Journal of Educational Computing Research, 32(3), 265-277.

Bonanno, R.A., \& Hymel, S. (2013). Cyber bullying and internalizing difficulties: Above and beyond the impact of traditional forms of bullying. Journal of Youth and Adolescence, 42(5), 685-697.

boyd, d., \& Marwick, A. (2011). Social privacy in networked publics: Teens' attitudes, practices, and strategies. Paper presented at the Oxford Internet Institute Decade in Internet Time Symposium, September 22, in Oxford, England.

Cook, C.R., Williams, K.R., Guerra, N.G., Kim, T.E., \& Sadek, S. (2010). Predictors of bullying and victimization in childhood and adolescence: A meta-analytic investigation. School Psychology Quarterly, 25, 2, 65-83.

Couvillon, M.A., \& Ilieva, V. (2011). Recommended practices: A review of schoolwide preventative programs and strategies on cyberbullying. Preventing School Failure, 55(2), 96101.

Davis, K. (2012a, April). Building community online: Opportunities, challenges, and the role of schools. Paper presented at the annual meeting of the American Educational Research Association, Vancouver, British Columbia, Canada.

Davis, K. (2012b). Friendship 2.0: Adolescents' experiences of belonging and self-disclosure online. Journal of Adolescence, 35 (6), 1527-1536.

Davis, K. (2012c). Tensions of identity in a networked era: Young people's perspectives on the risks and rewards of online self-expression. New Media \& Society, 14 (4), 634-651.

Davis, K. \& James, C. (2013). Tweens' conceptions of privacy online: Implications for educators. Learning, Media and Technology, 38(1), 4-25. 
Diazgranados Ferrans, S., Selman, R.L. \& Feigenberg, L.F. (2012). Rules of the culture and personal needs: Witnesses' decision-making processes to deal with situations of bullying in middle school. Harvard Educational Review, 82 (4), 445-470.

Didden R., Scholte R.H., Korzilius H., de Moor J.M., Vermeulen A., O'Reilly M., Lancioni G.E. (2009). Cyberbullying among students with intellectual and developmental disability in special education settings. Developmental Neurorehabilitation, 12(3), 146-51.

Dooley, J.J., Pyżalski, J., \& Cross, D. (2009). Cyberbullying versus face-to-face bullying. Journal of Psychology, 2174), 182-188.

Farrington, D., \& Ttofi, M. (2009). Reducing school bullying: Evidence-based implications for policy. Crime and Justice, 38(1), 281-345.

Finkelhor, D. (2013). Trends in bullying and peer victimization. Durham: University of New Hampshire, Crimes against Children Research Center.

Hinduja, S., \& Patchin, J.W. (2011). Bullying, cyberbullying, and sexual orientation. Cyberbullying Research Center.

Hinduja, S., \& Patchin, J.W. (2013). State cyberbullying laws: A brief review of state cyberbullying laws and policies. Cyberbullying Research Center. Available at: http://www.cyberbullying.us/Bullying and Cyberbullying Laws.pdf

Holfeld, B., \& Grabe, M. (2012). Middle school students' perceptions of and responses to cyber bullying. Journal of Educational Computing Research, 46(4), 395-413.

Jones, L.M., Mitchell, K.J., \& Finkelhor, D. (2012). Trends in Youth Internet Victimization: Findings from Three Youth Internet Safety Surveys 2000-2010. Journal of Adolescent Health, $50,2,179-186$.

Juvonen, J., \& Gross, E.F. (2008). Extending the school grounds? Bullying experiences in cyberspace. The Journal of School Health, 78, 9, 496-505.

Katzer, C., Fetchenhauer, D., \& Belschak, F. (2009). Cyberbullying: Who are the victims? A comparison of victimization in internet chatrooms and victimization in school. Journal of Media Psychology, 21(1), 25-36.

Kowalski, R.M., \& Fedina, C. (2011). Cyber bullying in ADHD and Asperger Syndrome populations. Research in Autism Spectrum Disorders, 5(3), 1201-1208.

Lenhart, A., Madden, M., Smith, A., Purcell, K., Zickuhr, K., \& Rainie, L. (2011). Teens, kindness, and cruelty on social network sites. Pew Internet and American Life Project. Available at: http://pewinternet.org/Reports/2011/Teens-and-social-media.aspx

Levy, N., Cortesi, S., Crowley, E., Beaton, M. Casey, J., \& Nolan, C. (September 2, 2012). Bullying in a networked era: $A$ literature review. The Kinder \& Braver World Project: Research Series No. 2012-17. Available at: http://papers.ssrn.com/sol3/papers.cfm?abstract id=2146877 
Limber, S.P. (2011). Development, evaluation, and future directions of the Olweus Bullying Prevention Program. Journal of School Violence, 10(1), 71-87.

Marwick, A.E. \& boyd, d. (2011). The drama! Teen conflict, gossip, and bullying in networked publics. A Decade in Internet Time: Symposium on the Dynamics of the Internet and Society, September 2011. Available at SSRN: http://ssrn.com/paper=1926349

Mitchell K.J., Ybarra M., \& Finkelhor D. (2007). The relative importance of online victimization in understanding depression, delinquency, and substance use. Child Maltreatment, 12(4), 314-24.

Molcho, M., Craig, W., Due, P., Pickett, W., Harel-Fisch, Y., Overpeck, M., \& HBSC Bullying Writing Group. (2009). Cross-national time trends in bullying behaviour 1994-2006: findings from Europe and North America. International Journal of Public Health, 54, 225-34.

O'Connell, P., Pepler, D., \& Craig, W. (1999). Peer involvement in bullying: Insights and challenges for intervention. Journal of Adolescence, 22 (4), 437-452.

Olweus, D. (1978). Aggression in the schools: Bullies and whipping boys. Washington, DC: Hemisphere.

Olweus, D. (1993). Bullying at school: What we know and what we can do. Oxford, UK: Blackwell.

Olweus D. (1994). Bullying at school: Basic facts and effects of a school based intervention program. Journal of Child Psychology and Psychiatry, 35(7), 1171-90.

Olweus, D. (2003). A profile of bullying at school. Educational Leadership, 60(6), 12-17. Pascoe, C. J. (2011). Resource and risk: Youth sexuality and new media use. Sexuality Research and Social Policy, 8(1), 5-17.

Pascoe, C.J. (2011). Resource and risk: Youth sexuality and new media use. Sex Res Soc Policy Sexuality Research and Social Policy, 8(1), 5-17.

Patchin, J., \& Hinduja, S. (2006). Bullies move beyond the schoolyard: A preliminary look at cyberbullying. Youth Violence and Juvenile Justice, 4, 148-169.

Pedersen, S. (2013). UK young adults' safety awareness online - is it a 'girl thing'? Journal of Youth Studies, 16(3), 404-419.

Pellegrini, A.D. (2002). Bullying and victimization in middle school: A dominance relations perspective. Educational Psychologist, 3オ3), 151-163.

Pellegrini, A.D. \& Long, J.D. (2002). A longitudinal study of bullying, dominance, and victimization during the transition from primary school through secondary school. British Journal of Developmental Psychology, 20(2), 259-280.

Raskauskas, J., \& Stoltz, A.D. (2007). Involvement in traditional and electronic bullying among adolescents. Developmental Psychology, 43(3), 564-75. 
Rigby, K., \& Smith, P.K. (2011). Is School Bullying Really on the Rise? Social Psychology of Education: an International Journal, 14, 4, 441-455.

Slonje R, \& Smith P.K. (2008). Cyberbullying: Another main type of bullying? Scandinavian Journal of Psychology, 49(2), 147-54.

Smith, P.K., Talamelli, L., Cowie, H., Naylor, P., \& Chauhan, P. (2004). Profiles of non-victims, escaped victims, continuing victims and new victims of school bullying. British Journal of Educational Psychology, 74(4), 565-581.

Smith, P.K., Madsen, K.C., \& Moody, J.C. (1999). What causes the age decline in reports of being bullied at school? Towards a developmental analysis of the risks of being bullied. Educational Research, 41(3), 267-85.

Smith, P.K. (2009). Cyberbullying: Abusive relationships in cyberspace. Zeitschrift für Psychologie/Journal of Psychology, 2174), 180-181.

Snell, P.A., \& Englander, E.K. (2010). Cyberbullying victimization and behaviors among girls: Applying research findings in the field. Journal of Social Sciences, 6(4), 510-514.

Swearer, S.M., Espelage, D.L., Vaillancourt, T., \& Hymel, S. (2010). What can be done about school bullying? Linking research to educational practice. Educational Researcher, 39(1), 38-47.

Ttofi M.M., \& Farrington D.P. (2011). Effectiveness of school-based programs to reduce bullying: A systematic and meta-analytic review. Journal of Experimental Criminology, 71 ), 2756.

Tokunaga, R. S. (2010). Following you home from school: A critical review and synthesis of research on cyberbullying victimization. Computers in Human Behavior, 26(3), 277-287.

Twemlow, S.W., Fonagy, P., \& Sacco, F.C. (2004). The role of the bystander in the social architecture of bullying and violence in schools and communities. Annals of the New York Academy of Sciences, 1036, 215-232.

Vandebosch, H., \& van Cleemput, K. (2008). Defining cyberbullying: A qualitative research into the perceptions of youngsters. Cyberpsychology \& Behavior, 11(4), 499-503.

Vandebosch, H., \& van Cleemput, K. (2009). Cyberbullying among youngsters: Profiles of bullies and victims. New Media and Society New Media and Society, 11(8), 1349-1371.

Walker, J. (2012). A "toolbox" of cyberbullying prevention initiatives and activities. In J.W. Patchin \& S. Hinduja (Eds), Cyberbullying prevention and response: Expert perspectives (pp. 128-148). New York: Routledge.

Wang, J., Iannotti, R.J., \& Nansel, T.R. (2009). School bullying among adolescents in the United States: Physical, verbal, relational, and cyber. The Journal of Adolescent Health, 45(4), 368-75.

Willard, N.E. (2007). Cyberbullying and cyberthreats: Responding to the challenge of online social aggression, threats, and distress. Champaign, Ill.: Research Press. 
Williams, K.R., \& Guerra, N.G. (2007). Prevalence and predictors of internet bullying. Journal of Adolescent Health, 41, 6.

Wolke, D., Copeland, W.E., Angold, A., \& Costello, E.J. (2013). Impact of bullying in childhood on adult health, wealth, crime, and social outcomes. Psychological Science.

Ybarra, M.L., boyd, d., Korchmaros, J.D., \& Oppenheim, J.K. (2012a). Defining and Measuring Cyberbullying within the Larger Context of Bullying Victimization. Journal of Adolescent Health, 51, 1, 53-58.

Ybarra, M.L., Diener-West, M., \& Leaf, P.J. (2007). Examining the overlap in internet harassment and school bullying: Implications for school intervention. Journal of Adolescent Health, 41 (6), 42-50.

Ybarra, M.L., Mitchell, K.J., \& Espelage, D.L. (2012b). Comparisons of bully and unwanted sexual experiences online and offline among a national sample of youth. In O. Ozdemir (Ed.) Complementary Pediatrics, ISBN: 978-953-51-0155-0, InTech, Available from:

http://www.intechopen.com/books/complementary-pediatrics/comparisons-of-bully-andunwanted-sexualexperiences-online-and-offline-among-a-national-sample-of-y

(C) Copyright of Journal of Youth Development $~$ Bridging Research and Practice. Content may not be copied or emailed to multiple sites or posted to a listserv without copyright holder's express written permission. Contact Editor at: patricia.dawson@oregonstate.edu for details. However, users may print, download or email articles for individual use.

ISSN 2325-4009 (Print); ISSN 2325-4017 (Online) 